\title{
Desenvolvimento de um infográfico sobre a igreja do Sagrado Coração de Jesus, em Juazeiro do Norte-CE
}

\author{
Development of an infographic about the church of the Sacred Heart of Jesus, \\ in Juazeiro do Norte-CE
}

Manoel Deisson Xenofonte Araujo, Emanuelly Cristyne Verissimo Evangelista, Benjamin Yousef Mariano do Nascimento, Sávio Nobre Araújo, Kalígia Silva Siqueira Cavalcante, Sarah Maria Fontes de Lima, Rita de Cássia Soares Brito

Infografia, Juazeiro do Norte, Padre Cícero

O presente artigo visa ilustrar o processo de desenvolvimento de um infográfico sobre a história e arquitetura de uma igreja que seria construída em na cidade de Juazeiro do Norte-CE, tendo como objetivo suprir essa carência visual e contribuir para a cristalização de uma memória e identidade local acerca da construção da cidade. Para tanto, utiliza-se dos estudos de Teixeira (2010), Moraes (2017), Lapolli e Vanzin (2016) e Lima $(2009 ; 2018)$ no que se refere às definições, classificações e metodologias de um infográfico. Espera-se dessa maneira que a apresentação do processo projetual possa contribuir como modelo para projetos futuros dentro da temática.

Infographics, Juazeiro do Norte, Padre Cícero

This article aims to illustrate the process of developing an infographic about the history and architecture of a church that would be built in the city of Juazeiro do Norte-CE, aiming to fill this visual deficiency and contribute to the crystallization of a memory and identity about the construction of the city. For that, we used the studies of Teixeira (2010), Moraes (2017), Lapolli and Vanzin (2016) and Lima (2009; 2018) with regard to the definitions, classifications and methodologies of an infographic. In this way, we hope that the presentation of our design process can contribute as a model for future projects within the theme.

\section{Introdução}

A infografia se constitui em um campo que objetiva tornar conceitos, mecanismos ou narrativas complexas em uma linguagem mais sintética e coerente para determinado público, se utilizando de elementos verbais, pictóricos e esquemáticos. A partir da difusão de infográficos em meios jornalísticos, bem como uma série de estudos e publicações que vêm sendo desenvolvidas, hoje é possível elencar determinadas características e metodologias que auxiliam o desenvolvimento de infográficos, tornando esta modalidade de representação mais replicável.

Dessa maneira, compreende-se que o infográfico hoje se configura em uma ferramenta que pode, além de descomplexificar informações, visibilizar histórias, fatos e objetos pertencentes a

Anais do $10^{\circ} \mathrm{CIDI}$ e $10^{\circ} \mathrm{CONGIC}$

Kelli C.A.S. Smythe, Rafael de Castro Andrade (orgs.)

Sociedade Brasileira de Design da Informação - SBDI

Curitiba | Brasil | 2021
Proceedings of the $10^{\text {th }} \mathrm{CIDI}$ and $10^{\text {th }}$ CONGIC

Kelli C.A.S. Smythe, Rafael de Castro Andrade (orgs.)

Sociedade Brasileira de Design da Informação - SBDI Curitiba | Brazil | 2021 
determinado contexto regional e cultural. Tal perspectiva torna-se ainda mais relevante em se tratando de estudos que visam reproduzir objetos históricos, arqueológicos e arquitetônicos que não pertencem mais à paisagem local, mas que são imprescindíveis para a constituição de uma identidade e memória afetiva de um grupo social.

É a partir deste pressuposto que o presente trabalho se debruça. Pretende-se ilustrar o desenvolvimento de um infográfico sobre um fato que compõe a história da cidade de Juazeiro do Norte: A construção da igreja do Sagrado Coração de Jesus, um enorme templo que foi idealizado pelo sacerdote e chegou a ser parcialmente erguido, sendo sua construção interrompida por ordens de autoridades eclesiásticas no fim do séc. XIX. Esta obra teve seus resquícios completamente soterrados a partir da construção da estátua do padre Cícero em 1969, no exato local em que seria a igreja.

Assim, o infográfico realizado tem como meta suprir essa carência visual e contribuir para a cristalização de uma memória e identidade local acerca da construção da cidade de Juazeiro. Espera-se que a apresentação do processo projetual possa contribuir como modelo para projetos futuros dentro da temática.

\section{Uma breve apresentação sobre infografia}

A infografia é aqui entendida como um campo que se encontra na intersecção entre o design, ilustração e informação (Moraes, 2017), se constituindo em um gênero de texto multimodal, ou seja, englobando elementos verbais, pictóricos e esquemáticos para compor a informação (Lima, 2018). Nesse sentido, concordamos com Lima (2009; 2018) e Teixeira (2010), ao elencarem como principal característica de um infográfico a indissociabilidade entre texto e imagem, no sentido em que a infografia deve formar uma simbiose entre estes dois elementos.

Por fim, dentro das variadas classificações de tipos de infográficos, adota-se aqui a proposta por Moraes (2017) a qual se baseia na natureza do discurso. Segundo o autor, os infográficos podem ser do tipo Historiográfico, Explanatório ou Exploratório. Nesse sentido, compreendemos que o projeto aqui realizado se constitui no tipo historiográfico, visto que pretende contextualizar um determinado elemento em relação a uma determinada sucessão de eventos históricos. A metodologia empregada envolveu as etapas de Pesquisa, Escopo e Produção, a qual também se estrutura o presente artigo.

\section{Resumo do conteúdo histórico}

A história que envolve o conteúdo do infográfico inicia-se em 1877, quando o povoado de Juazeiro enfrentou um longo período de seca. Vendo o estado de calamidade que atingia sua terra, o padre Cícero fez então uma promessa de erguer um santuário em honra ao Sagrado Coração, caso a estiagem terminasse (Neto, 2009).

Já no ano de 1889, houve chuvas abundantes. Com açudes transbordando e brejos alagados, o padre logo iniciou o cumprimento do voto, se utilizando de um terreno na chamada 
colina do Horto e contando com a mão de obra dos fiéis para carregar água, aterrar o terreno, quebrar e carregar pedra. Muitos destes iam ajudar também como forma de pagar promessas (Oliveira, 2001).

Em 1895 o alicerce já havia sido feito, mas a obra foi interrompida em decorrência dos acontecimentos que ficaram marcados como "O Milagre de Juazeiro"; uma sucessão de momentos em que uma beata chamada Maria de Araújo teria transformado a hóstia consagrada pelo Padre Cícero em sangue ao engoli-la. Este suposto milagre não agradava ao Bispo do Ceará D. Joaquim, o qual passa a perseguir e punir o Padre Cícero (Neto, 2009).

Quando a parte central já estava pronta para receber a cobertura, D. Joaquim proibiu a continuação das obras, que foram suspensas em 1896 e demolidas em 1934, período em que se tornou um dos roteiros de peregrinação e adoração de romeiros. No ano de 1969, a famosa estátua do Padre Cícero foi construída no exato local onde seria a igreja, soterrando assim os resquícios desta construção e obstando a manutenção de uma memória coletiva em torno desta empreitada.

\section{Pesquisa e escopo}

A primeira parte da pesquisa envolveu uma consulta do acervo fotográfico do historiador juazeirense Renato Casimiro ${ }^{1}$. Através desse recurso, juntamente com os relatos do período narrados pelo mesmo, foi possível traçar uma linha do tempo que demonstrasse a ascensão do projeto, sua construção e posteriormente sua ruína.

As fotografias da época da construção datam de períodos diferentes, possibilitando a visualização da degradação que sofreu, além de elucidar sua localização a partir de outros pontos geográficos. Isso permitiu o desenvolvimento de uma linha do tempo ilustrada para o infográfico. Outras fotografias foram úteis para supor o tamanho da construção completa, a partir da comparação entre as proporções humanas:

\footnotetext{
${ }^{1}$ O professor Renato Casemiro é graduado em Química Industrial (1971) e em Engenharia Química (1972), pela Universidade Federal do Ceará. Desde 1967 dedica-se a estudos e pesquisas sobre História do Ceará, se dedicado atualmente a projetos nas áreas de preservação da memória histórica de Juazeiro do Norte. Fonte: < http://lattes.cnpq.br/3162916937096910>
} 
Figura 1: Fotografias que trazem um comparativo do tamanho da construção em relação aos indivíduos. Fonte: Acervo de Renato Casemiro.
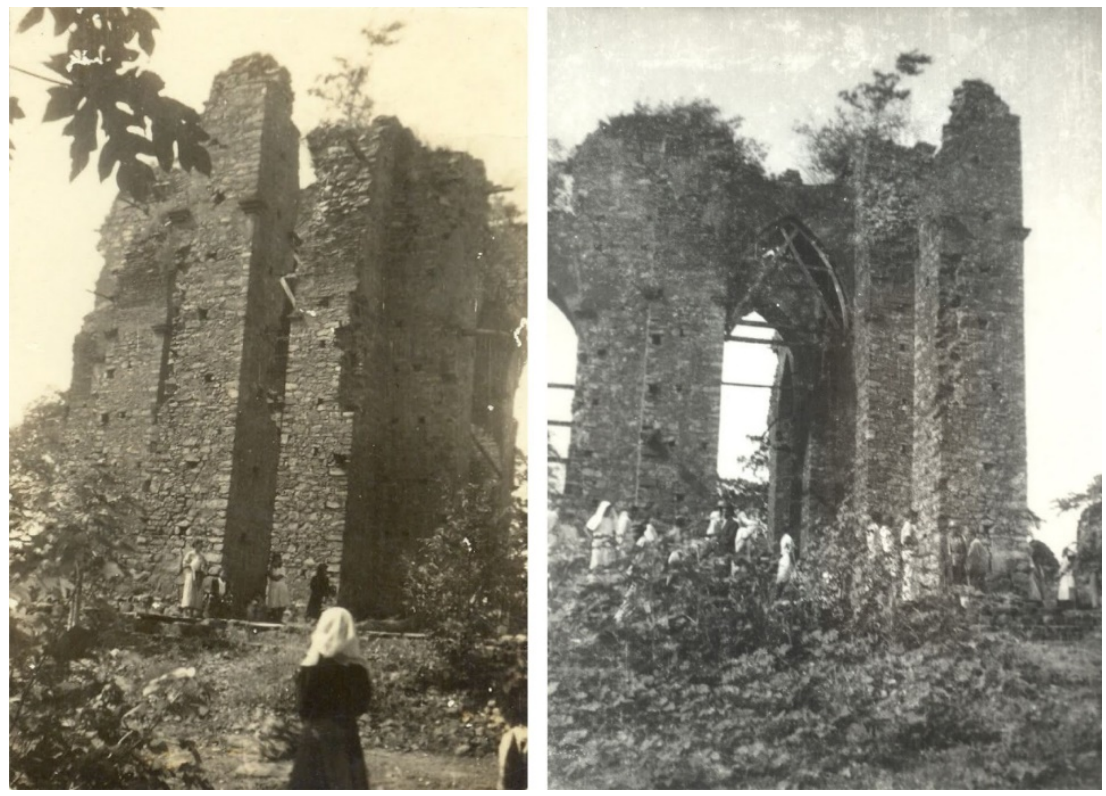

Ao unir essas informações com os registros fotográficos de uma maquete do projeto produzida por Pedro Coutinho em meados de 1920 -, obtidos após a visita presencial ao museu da Casa do Padre Cícero, foi possível visualizar o conceito da estrutura, as partes que a compunham e sua proporção.

Figura 2: Pedro Coutinho e sua maquete, aprox. 1920. Fonte: Acervo de Renato Casemiro

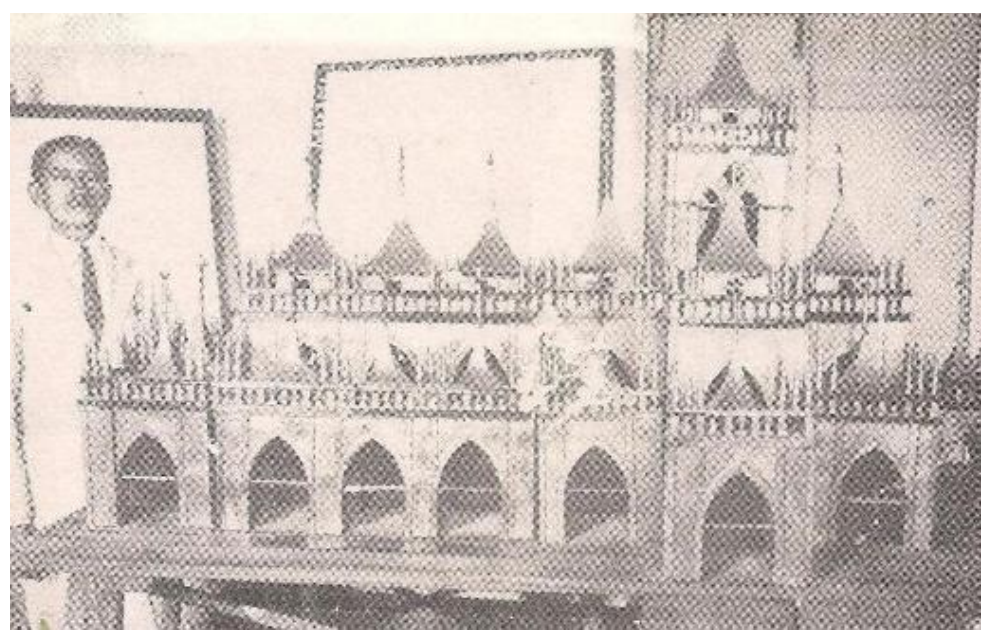


Figura 3: Maquete em exposição no museu padre Cícero. Fonte: Acervo dos autores
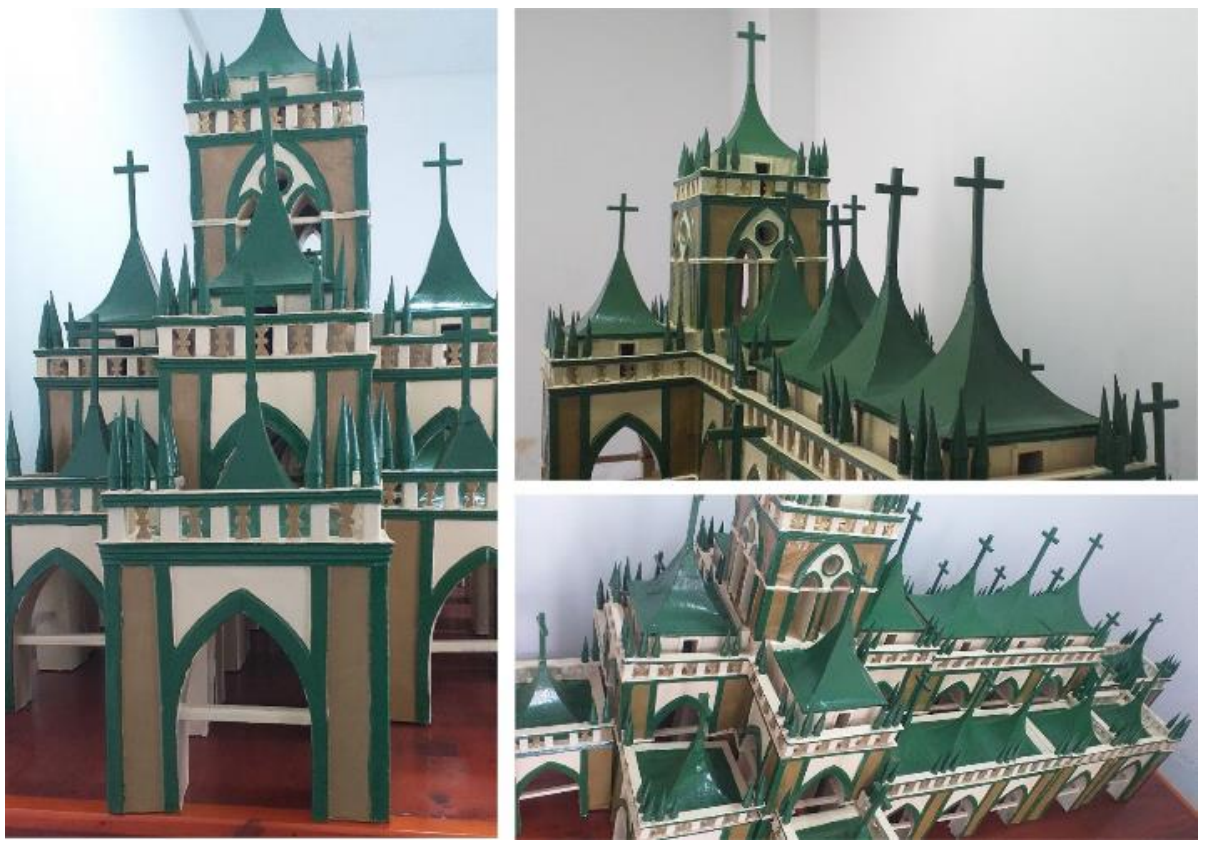

A partir da pesquisa de referências de igrejas em estilo gótico, houve algumas adaptações no modelo tridimensional em relação à maquete existente. Uma dessas diz respeito aos pináculos presentes na maquete, os quais são elementos arquitetônicos geralmente utilizados como decoração ou reforço estrutural na arquitetura gótica (Mcnamara, 2017). Os aspectos que constituem a forma dos pináculos na maquete são de base circular com acabamento cônico, mas analisando as referências da época das construções de pináculos em catedrais e igrejas, acreditamos que em sua construção física estes seriam de base hexagonal ou octogonal até a sua extremidade pontiaguda.

Figura 4: Pináculos presentes na maquete e pináculos executados no modelo 3d. Fonte: Desenvolvido pelos autores
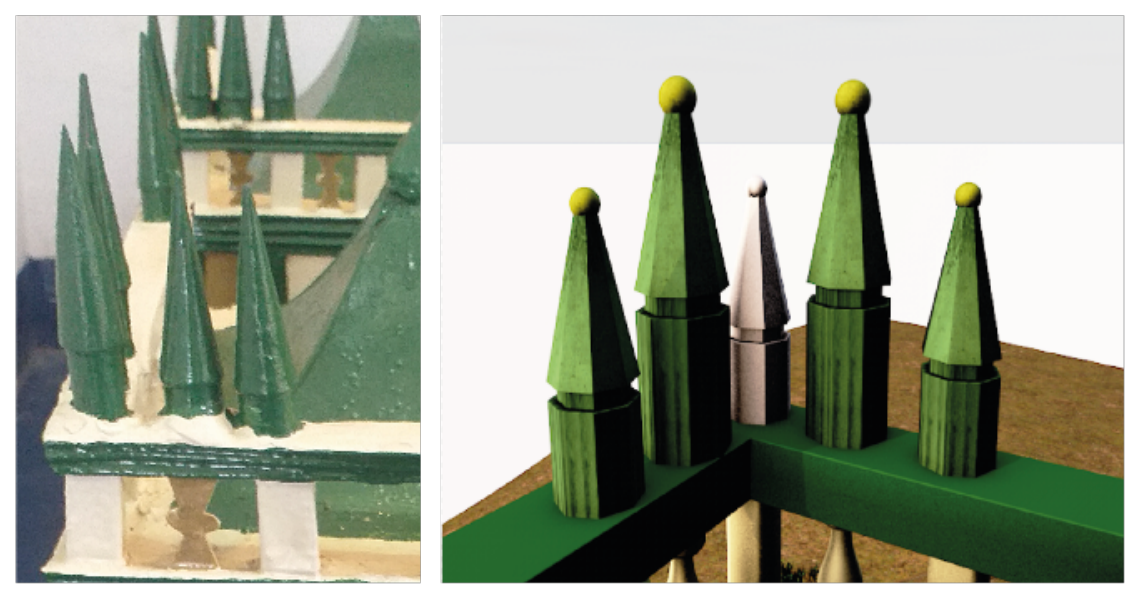
Na maquete há ainda elementos presentes nas sacadas da igreja, cujos contornos nos remetem à balaústres; estruturas semelhantes a colunas e geralmente utilizados em corrimãos de escadas e parapeitos. Nas igrejas góticas são mais utilizados em grades de ferro, sendo os balaústres maciços mais comuns às fachadas do movimento maneirista, algo que evidencia o caráter eclético deste projeto ${ }^{2}$.

Foi realizada também uma busca por infográficos como referência, focando em exemplares das revistas "Mundo Estranho" e "Superinteressante" da editora abril, publicados entre os anos de 2012 e 2017. O infográfico histórico "Como a Muralha da China foi construída" (Figura 5), foi uma das principais referências de diagramação e aplicação das ilustrações. A partir disso optou-se por desenvolver ilustrações dos personagens históricos envolvidos, enquanto a igreja e os demais elementos da paisagem seriam realizados a partir de modelagem e renderização 3d. Dessa maneira, delineou-se o escopo do infográfico, onde a ênfase estaria na estrutura arquitetônica e sua localização na colina do Horto, tendo como informações secundárias os personagens envolvidos neste projeto.

Figura 5: Infográfico utilizado como referência visual. Fonte: Revista Mundo estranho, fevereiro de 2017

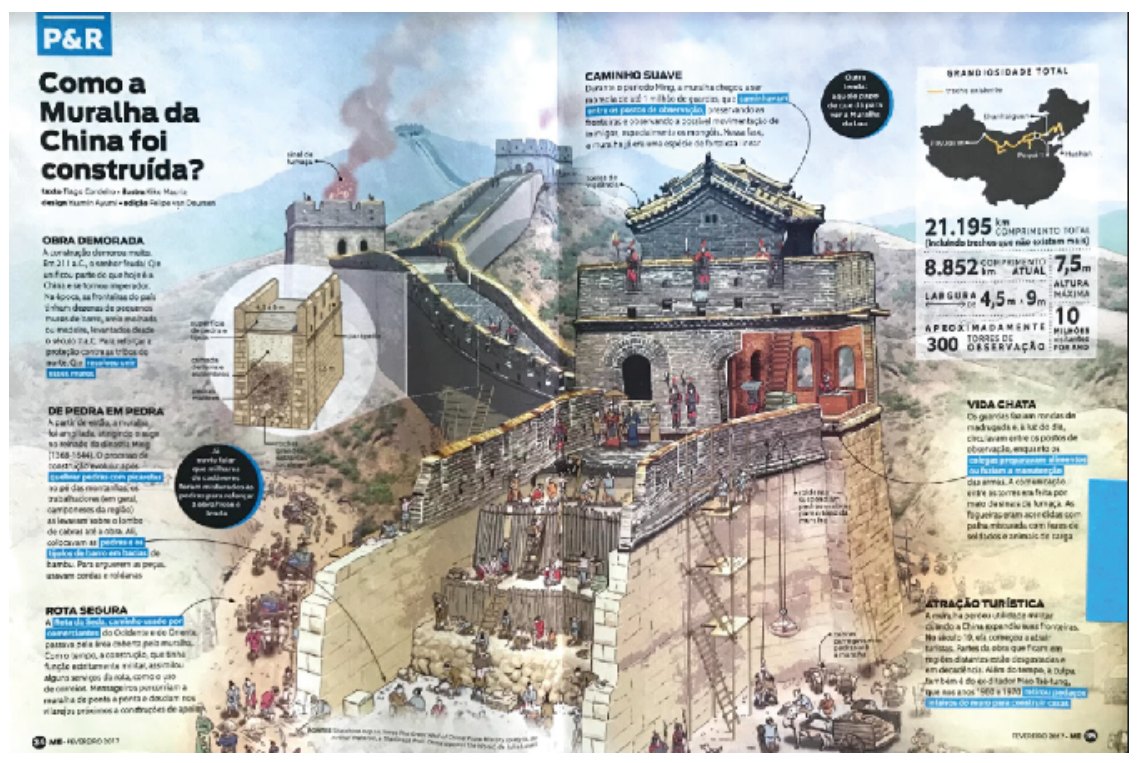

\section{Produção}

A primeira etapa da produção se deu pelo desenvolvimento de uma maquete $3 \mathrm{~d}$ da igreja a partir das referências fotográficas encontradas e da maquete física encontrada no museu "Casa do Padre Cícero". Para tanto, foi utilizado o software Cinema 4d, tanto para a modelagem quanto para a renderização. O desenvolvimento dos componentes editoriais do projeto ocorreu inicialmente na plataforma de compartilhamento Miro, onde, a partir de experimentações

2 Disponivel em:<https://www.hisour.com/pt/baluster-29168/> Acesso em: 05/05/2021 
iniciais coletivas de layout e das representações em 3D, houve a delimitação dos elementos pictóricos, esquemáticos e textuais que comporiam o infográfico. Após a definição dos mesmos, a execução continuou no software de editoração Adobe InDesign. Tendo em vista uma possível publicação impressa, delimitamos o tamanho do infográfico para o formato padrão de página dupla em revista: $42 \times 28 \mathrm{~cm}$.

Figura 6: Maquete 3d e ilustração de personagens. Fonte: Desenvolvido pelos autores
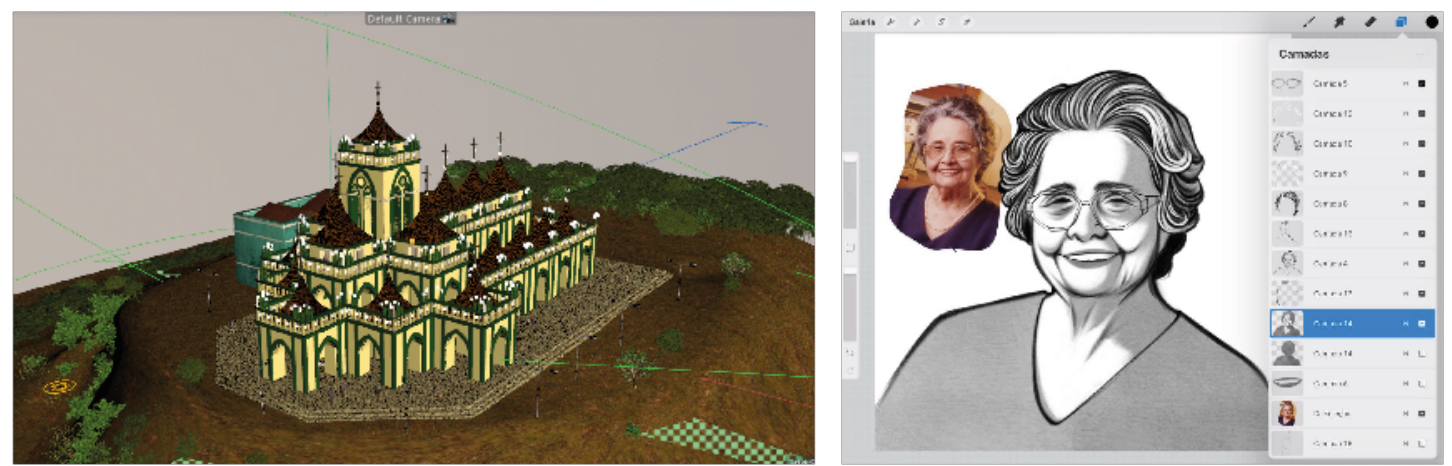

A escolha das medidas do infográfico, seu grid e tipografia, tinham como objetivo principal a legibilidade dos textos e a organização da estrutura que conciliaria o volume textual com as informações imagéticas. Devido à grande quantidade de informações que seriam anexadas ao corpo do trabalho, as tipografias foram escolhidas, pensando não somente no peso, mas também no espaçamento, entrelinhamento, e serifa, que deveriam administrar bem o volume das informações com pesos diferentes. Sendo assim, foi delimitado o uso das tipografias Medula One para o título do infográfico, e Crimson Pro para o corpo do texto, ambas disponibilizadas gratuitamente pela plataforma Google Fonts. Segue abaixo o resultado: 
Figura 7: Versão final do Infográfico. Fonte: Desenvolvido pelos autores

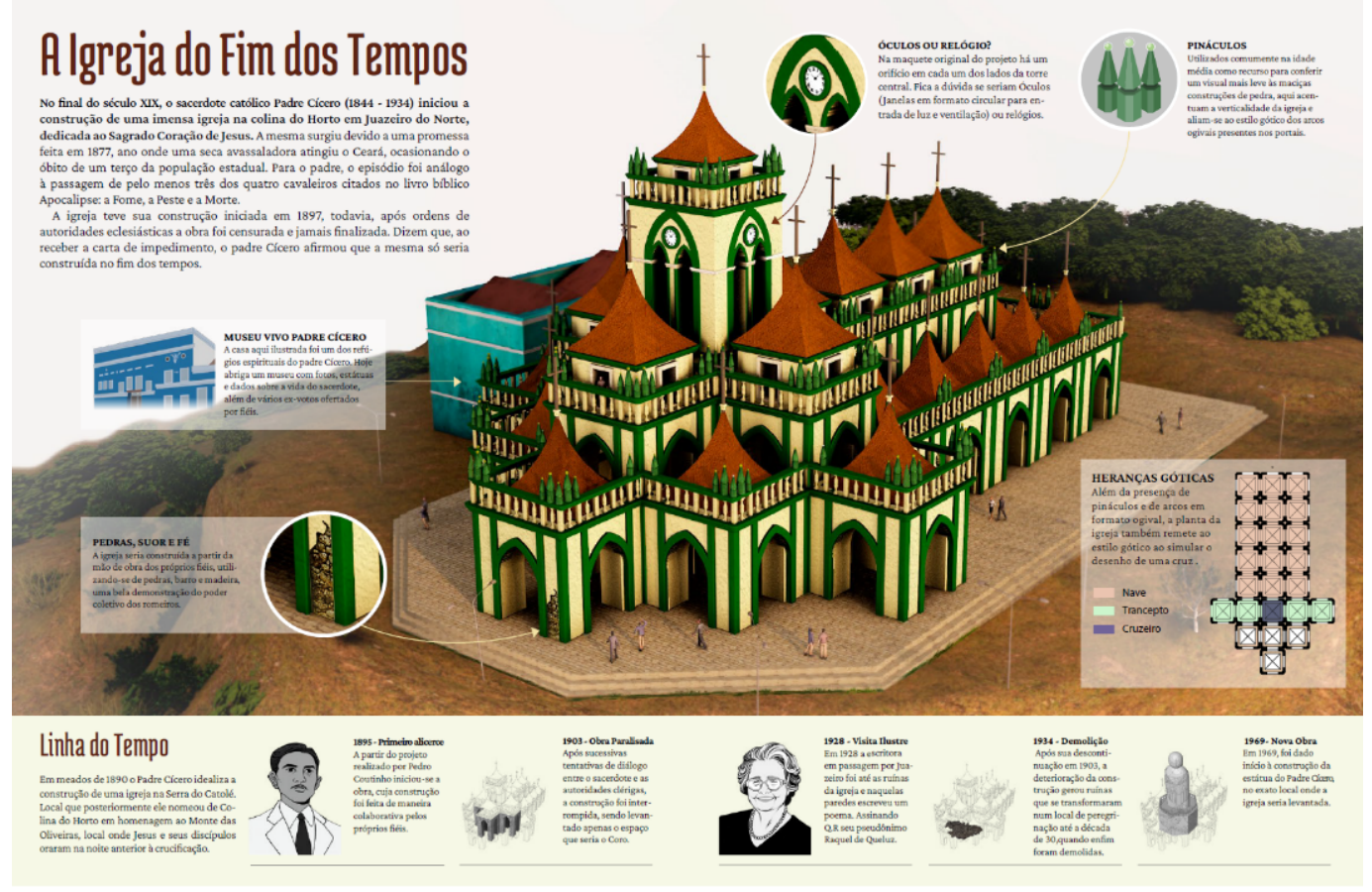

Figura 8: Detalhe de informação complementar no infográfico. Fonte: Desenvolvido pelos autores

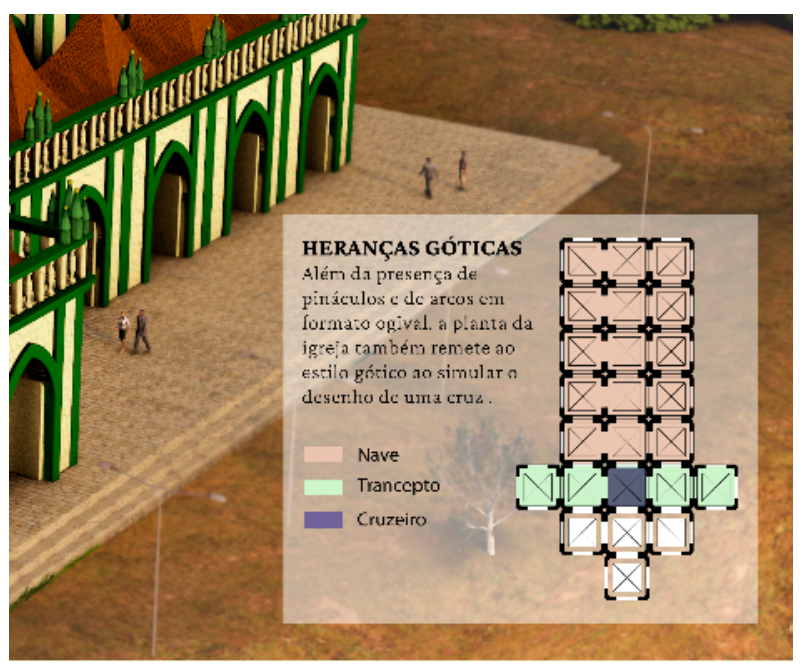

Figura 9: Detalhe de informação principal no infográfico. Fonte: Desenvolvido pelos autores

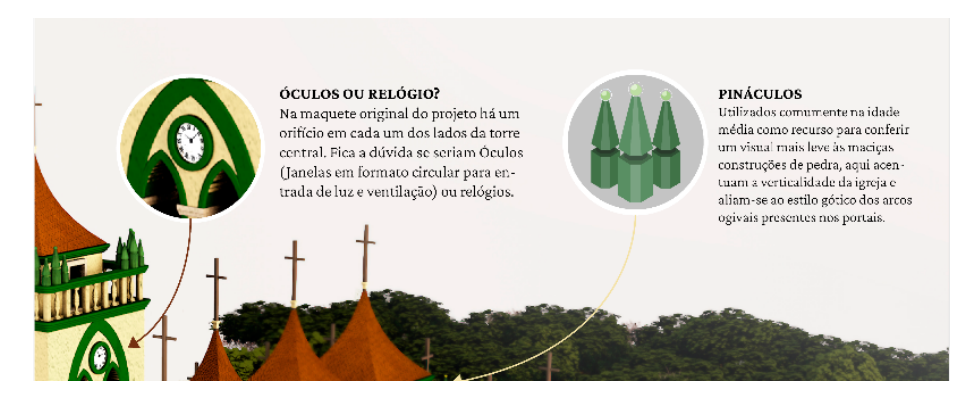


Figura 10: Detalhe do leading e informação principal no infográfico. Fonte: Desenvolvido pelos autores

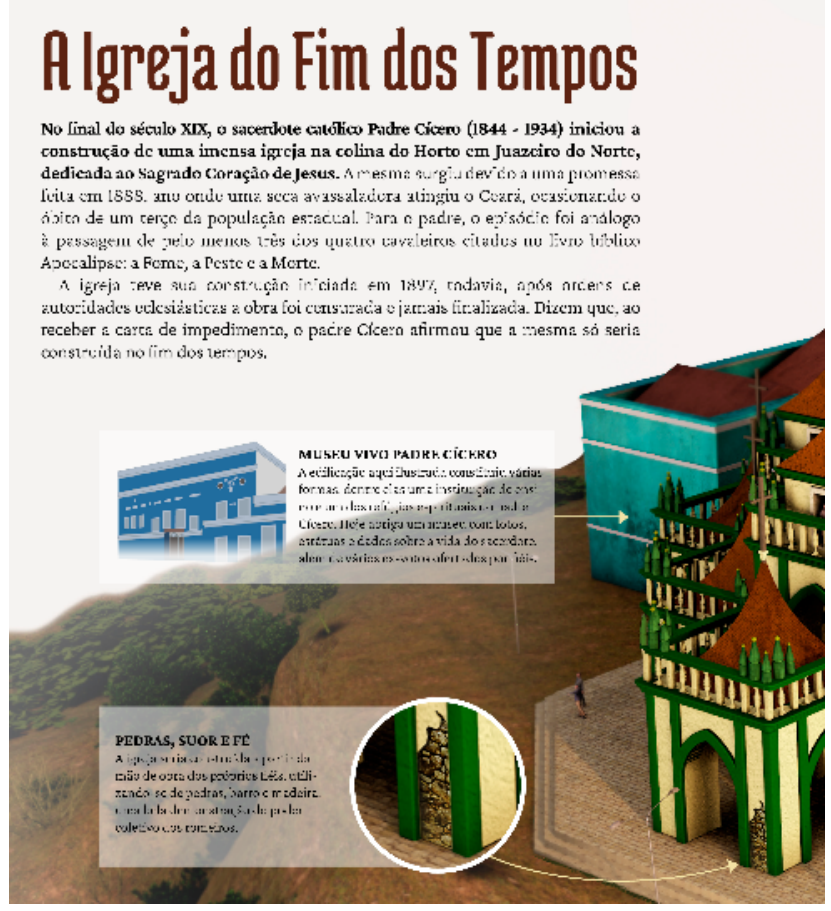

Figura 11: Detalhe da linha do tempo no infográfico. Fonte: Desenvolvido pelos autores

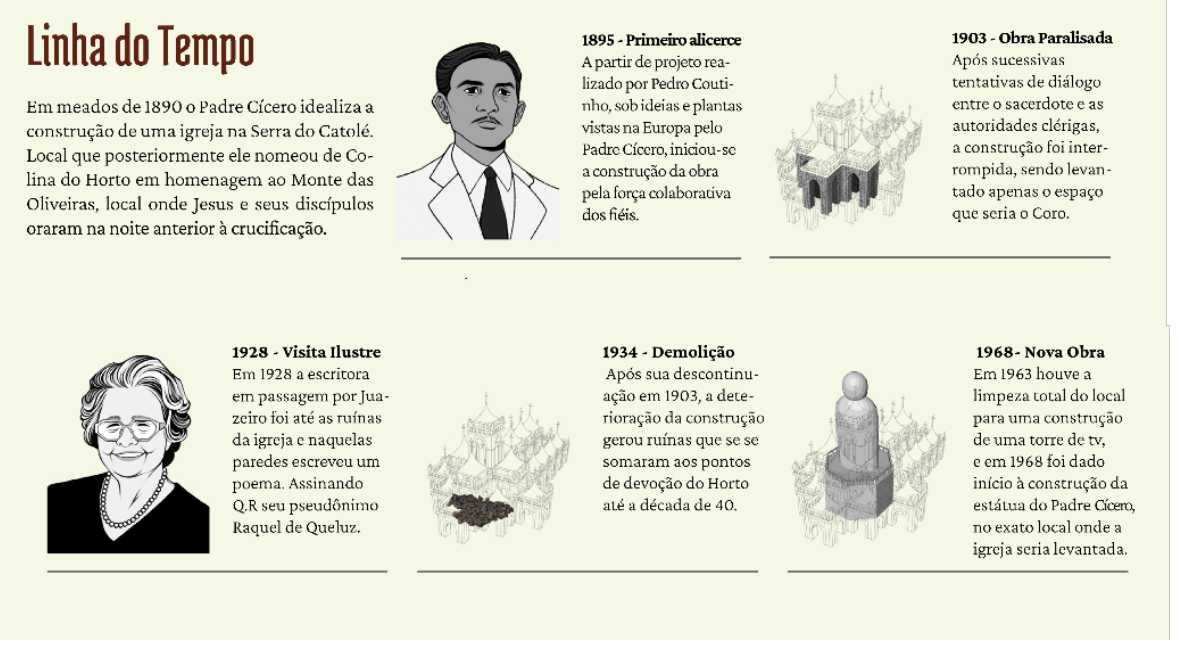

\section{Considerações finais}

Uma das dificuldades encontradas no desenvolvimento da pesquisa está atrelada ao fato de não se ter um projeto arquitetônico antecessor à maquete, a qual foi a principal fonte imagética para a construção do infográfico. Para que a igreja fosse representada em sua forma mais autêntica, o projeto seria fundamental para que a composição da imagem fosse o mais próximo do planejado a ser construído na época.

É importante reforçar que se trata de um infográfico com fins didáticos, no intuito de representar um evento histórico que possui poucas representações visuais. Nesse sentido, a 
ilustração não tem a pretensão de ser exatamente fiel ao que seria construído, mas se constituir em uma ferramenta para disseminar informações importantes sobre a localização da construção e a sua grandiosidade.

Espera-se assim contribuir para o resgate desse capítulo perdido na história, assim como para a criação de novos projetos infográficos que possam compartilhar desse mesmo objetivo.

\section{Referências}

Junior, Roberto (2021). A igreja do Horto, o templo da missa do fim dos tempos. Crato, 2021. Disponível em: <https://cariridasantigas.com.br/a-igreja-do-horto-o-templo-da-missa-do-fimdos-tempos/>. Acesso em: 29 de abril de 2021

Lapolli, Mariana; Vanzin, Tarcísio (2016). Infografia na era da cultura visual. Pandion. Florianópolis.

Lima, R. C. (2009). Análise da infografia jornalística. 2009. 143 f. Dissertação de Mestrado em Design, Escola Superior de Desenho Industrial (ESDI/UERJ), Rio de Janeiro.

Lima, R. C. (2018) A metáfora visual e enquadramento na infografia: o enfoque nos gráficos estatísticos. 2018. 191f. Tese (Doutorado em Design) - Escola Superior de Desenho Industrial (ESDI/UERJ), Rio de Janeiro.

Mcnamara, R. Denis (2017). How to read churches. New York: Rizzoli International Publications.

Moraes, Ary (2017). Infografia: história e projeto. São Paulo: Blucher.

Neto, Lira (2009). Padre Cícero: Poder, fé e guerra no sertão. Companhia das Letras, Brasil.

Oiveira, Amália Xavier de (2001). O Padre Cícero que eu Conheci: Verdadeira História de Juazeiro.Premius, Fortaleza.

Teixeira, Tattiana (2010). Infografia e Jornalismo: conceitos, análises e perspectivas. EduFBA, Salvador.

\section{Sobre os autores}

Manoel Deisson Xenofonte Araujo, Me., UFCA, Brasil <deisson.araujo@ufca.edu.br> Emanuelly Cristyne Verissimo Evangelista, UFCA, Brasil <emanuelly.00159@gmail.com> Benjamin Yousef Mariano do Nascimento, UFCA, Brasil <benjaminyouseff@gmail.com> Sávio Nobre Araújo, UFCA, Brasil <araujo.n.savio@gmail.com> Kalígia Silva Siqueira Cavalcante, UFCA, Brasil <kaligiasiqueira@gmail.com> Sarah Maria Fontes de Lima, UFCA, Brasil <sarah.maria@aluno.ufca.edu.br> Rita de Cássia Soares Brito, UFCA, Brasil <cassiasoares8011@gmail.com> 